\title{
A noiva estava de vermelho: horror e sexualidade em "A mulher que inventou 0 amor"
}

\section{Tiago José Lemos Monteiro'}

Instituto Federal do Estado do Rio de Janeiro

\section{Resumo}

A mulher que inventou o amor (1979) é um longa-metragem brasileiro dirigido por Jean Garrett, escrito por João Silvério Trevisan e fotografado por Carlos Reichenbach. O filme se apropria abertamente de alguns códigos estilísticos e narrativos vinculados a um imaginário de gênero (no caso, o horror e o melodrama), ao mesmo tempo em que se mostra disposto a tensionar estes mesmos elementos, reenquadrando-os sob uma perspectiva singular em relação às questões de gênero, sexualidade e representação. O ponto de partida da trama é, até certo ponto, alinhado à sub-vertente dos rape \&u revenge movies, tendência então em voga no âmbito do horror de exploração internacional. No filme, entretanto, o estupro sofrido pela personagem Doralice (Aldine Müller) serve de catalisador para uma vingança direcionada contra todos os homens (em sua maioria, representados como fracos, patéticos, egoístas ou aproveitadores) que atravessam seu caminho.

\section{Palavra-chave}

Boca do Lixo; Jean Garrett; "A mulher que inventou o amor"; horror; exploitation

\section{Introdução}

Este trabalho se insere no contexto de um esforço de investigação que tem por objetivo o resgate das memórias da produção cinematográfica sediada na re-

\footnotetext{
1 Tiago José Lemos Monteiro é doutor em Comunicação pela Universidade Federal Fluminense. Professor efetivo do Curso de Produção Cultural do Instituto Federal de Educação, Ciência e Tecnologia do Rio de Janeiro. Estágio pós-doutoral junto ao Programa de Pós-Graduação em Comunicação da Universidade Anhembi Morumbi concluído em 2017. tjmonteiro@gmail.com
} 
gião da Boca do Lixo paulistana entre as décadas de 1960 e 1980, para além das dicotomias que vêm caracterizando algumas das abordagens mais frequentes sobre este universo, quais sejam: por um lado, a atribuição de estigmas que irão associar a produção da Boca a um cinema apelativo, de baixa qualidade, ideologicamente conservador e esteticamente irrelevante; por outro, uma tendência contemporânea à celebração eufórica de artistas e filmes subitamente convertidos em mestres e obras-primas injustamente vilipendiados pelo pensamento crítico hegemônico de então.

A busca por um "caminho do meio" entre essas duas perspectivas nos permite, em contrapartida, tratar os filmes oriundos da Boca como documentos de sua época, atravessados por todas as ambiguidades que caracterizam a cultura midiática de maneira geral. O caráter ambivalente da produção da Boca se manifesta não apenas no conjunto das obras e relações sociais e afetivas lá estabelecidas, mas também nas trajetórias individuais de determinados profissionais, e mesmo na singularidade de um único filme - como parece ser o caso do objeto deste artigo.

A mulher que inventou o amor é um longa-metragem brasileiro de 1980, dirigido por Jean Garrett (1946-1996), escrito por João Silvério Trevisan (1944-) e fotografado por Carlos Reichenbach (1945-2012). O filme narra a saga existencial e erótica de Doralice (interpretada pela atriz Aldine Müller), moça ingênua e humilde que, logo na sequência inicial da trama, é violentada por um açougueiro, recebendo em troca alguns pedaços de carne. Incentivada por uma amiga, ela adentra o mundo da prostituição, onde aprende a controlar os homens mediante a simulação do próprio prazer, consagrando-se no bas fond como "a Rainha do Gemido". Ao mesmo tempo, Doralice alimenta o sonho de se casar de véu e grinalda com o galã de telenovelas Cesar Augusto (Zecarlos de Andrade). Ao longo de sua jornada, os caminhos de Doralice se cruzam com os de diversos homens, em sua maioria, representados como fracos, patéticos, egoístas ou aproveitadores. Um deles, o Doutor Perdigão (Rodolfo Arena), decide transformá-la em uma dama da alta sociedade, matriculando-a em um curso de boas maneiras, a partir do qual ela gradativamente assume uma nova identidade - a vampírica, performática e não-normativa Tallullah, que termina por assassinar o objeto máximo de sua afeição em uma espécie de ritual de amor e morte (A MULHER, 1980).

Tradicionalmente associado ao ciclo de produção cinematográfica de endereçamento popular-massivo da Boca do Lixo paulistana, A mulher que inventou o amor se revela representativo das tensões e ambiguidades que caracterizam parte substancial deste universo, sobretudo em sua tentativa de alcançar uma espécie de "terceira via" entre a estética da exploração que pautava a maioria dos títulos provenientes da Boca, e as propostas artísticas tidas como mais sofisticadas que diversos cineastas logravam empreender (ORMOND, 2016). Por um lado, A mulher que inventou o amor se apropria abertamente de alguns códigos estilísticos e narrativos vinculados a um imaginário horrífico e melodramático; por outro, se mostra disposto a tensionar estes mesmos elementos, ao reenquadrá-los sob uma perspectiva consideravelmente distinta daquela que pautava as incursões mais convencionais 
da Boca em relação às questões de gênero, sexualidade e representação (MONTEIRO, 2019).

\section{A mulher que inventou o amor como exemplar de rape \& revenge à brasileira}

As possíveis conexões entre a produção audiovisual oriunda da Boca do Lixo paulistana entre as décadas de 1960 e 1980, e a estética da exploração (ou exploitation) em voga no âmbito de um certo cinema popular-massivo internacional do mesmo período já foram aventadas e debatidas por diversos autores em momentos anteriores da nossa (ainda incipiente) reflexão acadêmica sobre o tema (ABREU, 2002; PIEDADE, 2002; MONTEIRO, 2018).

O período compreendido entre as décadas de 1960 e 1980 registra a eclosão de inúmeras vagas de produção cinematográfica popular-massiva e de gênero nos mais variados contextos nacionais, e com expressivo retorno de bilheteria no âmbito de seus respectivos mercados internos, em países como Brasil e Argentina, mas também Itália, Japão, França e Austrália. Não existe uma explicação consensual que abranja a diversidade dessa produção, mas é possível identificar alguns elementos comuns a atravessar todos estes cenários. Em primeiro lugar, uma posição (eminentemente) periférica em relação ao "centro" Hollywood, sobretudo no que diz respeito à distribuição e à exibição; em segundo lugar, a adoção da prática do "similar nacional", com o objetivo de aproveitar a repercussão de algum êxito de bilheteria do cinema internacional devidamente "traduzido" para o contexto cultural em questão; em terceiro lugar, uma apropriação sistemática dos códigos de um ou mais gêneros narrativos, às vezes dentro de um mesmo filme; por fim, mas não menos importante, a representação propositadamente excessiva ou sensacionalista de algum tema considerado tabu ou controverso (sexo, nudez, drogas, sangue, violência), pelo seu valor enquanto atração (SCHAEFER, 1999; TOHILL \& TOMBS, 1995).

Dentre as várias características da lógica de exploração, uma em particular nos interessa para fins deste trabalho: a ideia de "similar nacional", manifesta em um esforço de "tradução" ou "apropriação" de subvertentes do cinema popular-massivo e de gênero internacional para a realidade brasileira de então, a partir de preocupações, cenários ou pautas específicas do nosso contexto sociocultural. Tomando por referência absoluta a produção mainstream dos estúdios de Hollywood, que atravessava um novo período de renascimento a partir de meados dos anos 1970 com o advento do modelo de blockbuster high concept, a lógica do similar nacional preconizava que qualquer sucesso de bilheteria poderia ser o objeto de uma "versão" brasileira (ou italiana, ou espanhola, ou francesa...), devidamente adequada à disponibilidade orçamentária (quase sempre limitada) e à estrutura menos ou mais industrial (geralmente, menos) do país em questão.

Em alguns casos, a tais elementos poderão ser acrescentadas variáveis locais como uma atmosfera de liberalização dos costumes favorecida pelo término 
de regimes ditatoriais e/ou conservadores de longa duração (como no Brasil e na Espanha); a promulgação de leis estabelecendo "cotas de tela" ou fomentando a produção nacional (caso da França); ou mesmo a existência de um cenário econômico favorável, após o período de recuperação do pós-guerra (particularmente no que diz respeito a alguns países europeus, como a Itália).

Em paralelo ao que também se observa em países anglófonos e hispânicos, os estudos fílmicos brasileiros contemporâneos têm se dedicado a um resgate cada vez mais sistemático de cinematografias e contextos de produção tradicionalmente situados às bordas dos cânones cinematográficos nacionais (LYRA \& SANTANA, 2006; SCONCE, 2007). Podemos identificar ressonâncias desses processos na redescoberta/revaloração da produção audiovisual oriunda da Boca do Lixo paulistana. A expressão "Boca do Lixo" nomeia uma região do centro da cidade de São Paulo onde, desde meados dos anos 1940, instalam-se diversos escritórios e estúdios de companhias cinematográficas nacionais e estrangeiras, atraídas pela proximidade em relação à Estação de Trens da Luz, que facilitaria o transporte de cópias e maquinário para o interior do estado e, por extensão, do país como um todo.

Fazendo jus à alcunha que, de modo pejorativo, a região recebeu por parte da imprensa, na Boca do Lixo criminosos arraia-miúda, profissionais do sexo e poetas de sarjeta conviviam de forma harmônica com o pessoal do cinema, igualmente heterogêneo em sua constituição. Realizadores de perfil e aspirações mais intelectuais compunham equipes com técnicos de origem humilde ou proletária, não raro pouco alfabetizados, e de formação puramente instintiva ou autodidata. Desta insólita mistura, resultaram aproximadamente mil filmes, produzidos entre as décadas de 1960 e 1980, que transitavam entre a comédia de costumes e o thriller policial, entre o musical de temática sertaneja e o faroeste, e nos quais a presença do elemento erótico era uma constante, independendo do gênero em questão (ABREU, 2002).

A vinculação entre a produção da Boca e a ideia de um cinema de exploração pode ser associada particularmente ao chamado sexploitatition e, nesse sentido, sua condição de celeiro de pornochanchadas (título pejorativo atribuído a comédias eróticas inspiradas no modelo italiano, nos anos 1960) se dava no âmbito de uma estratégia de desqualificação daqueles filmes que, dado seu caráter muitas vezes precário e (necessariamente) apelativo - visto que inserido em uma lógica industrial e de mercado (RAMOS, 2008, p. 178-195) - tendiam a ser julgados como sintomas do nosso subdesenvolvimento (BERNARDET, 2009, p. 210-215). Não obstante, por vezes o discurso que metonimizava o caráter conservador e moralista de alguns filmes (e seus autores) no caráter conservador e moralista de todos os filmes serviu de bode expiatório para que o cinema da Boca fosse, muitas vezes, enxergado como porta-voz da ideologia conformista do Governo Militar.

Mas, ao contrário do que o senso comum consagrou, na Boca do Lixo, não eram produzidas apenas pornochanchadas ou filmes necessariamente conservadores. Havia também thrillers policiais, westerns, comédias rasgadas, 
películas de horror e melodramas. Igualmente diversificadas eram as propostas estéticas de seus realizadores: na Boca, conviviam a anarquia sensual de Carlos Reichenbach (Império do desejo, 1980; Extremos do prazer, 1983) e as inquietações metafísicas de Walter Hugo Khouri (As filhas do fogo, 1978; Eros, o deus do amor, 1981); Alfredo Sternhein explorava os conflitos sentimentais da burguesia (Herança dos devassos, 1979) enquanto Francisco Cavalcanti dava vazão aos instintos de vingança das classes populares (Horas fatais, 1987); as pequenas crônicas urbanas de Claudio Cunha (Amada amante, 1978) dividiam espaço com as odisseias eróticas de David Cardoso (Dezenove mulheres e um homem, 1977).

$\mathrm{Na}$ virada para os anos 1980, com a entrada gradual do cinema pornográfico internacional no Brasil (quase sempre, por intermédio de medidas judiciais), os realizadores da Boca começam, pouco a pouco, a tensionar os limites da representação de temas-tabu em seus filmes, até que a crise política e econômica que assola o Brasil da metade dos anos 1980 em diante; a hegemonia construída pelo cinema de entretenimento hollywoodiano; e a guinada da Boca do Lixo rumo à febre do sexo explícito põe um fim às aspirações industriais da Rua do Triunfo (GODINHO \& MOURA, 2012). Mesmo realizadores de perfil híbrido, situados algures entre a pretensão de alguma sofisticação formal e o desejo de reconhecimento pelo grande público, vêem suas carreiras sofrendo bruscas - e, em muitos casos, definitivas - rupturas na segunda metade da supracitada década.

Partindo do pressuposto de que ambas as esferas compartilham um sem-número de pontos em comum - quais sejam, o caráter apelativo e sensacionalista de títulos, materiais publicitários e estratégias de divulgação; a ênfase no erotismo e em uma certa perspectiva objetificada sobre o corpo feminino desnudo; o endereçamento às audiências masculinas e proletárias dos grandes centros urbanos; e, por fim, o manejo consciente dos códigos de gêneros narrativos cinematográficos, a partir da noção de "similar nacional" - restaria verificar em quais aspectos o Cinema da Boca e o exploitation divergem de forma substancial (DENNISON, 2009).

Uma primeira caraterística a se destacar diz respeito ao circuito exibidor que, pelo menos no caso do cinema de exploração internacional, tradicionalmente se articulou em torno de salas e regiões específicas - os grindhouses - e que, no contexto brasileiro, parece ter ocupado os principais espaços de exibição das metrópoles urbanas e também se espraiado para as salas dos subúrbios, periferias e cidades do interior, menores e mais precárias e termos de infraestrutura. Uma segunda característica estaria relacionada ao contexto político e social atravessado pelo Brasil na "fase áurea" do cinema da Boca do Lixo e das relações entre o cinema brasileiro e seu público (entre 1975 e 1982, aproximadamente), no que diz respeito à coexistência entre tais produções e uma Ditadura Civil-Militar em curso, mediando as relações (ora tensas, ora harmônicas), entre os produtores vinculados à Boca do Lixo e as instâncias oficiais de fomento à produção e distribuição cinematográficas (como a Embrafilme).

$\mathrm{Na}$ medida em que os filmes da Boca materializavam certos esforços de "tradução" de subvertentes do cinema de exploitation internacional para a reali- 
dade brasileira de então, a partir de preocupações ou pautas específicas do nosso cenário sociocultural, $A$ mulher que inventou o amor também pode ser enquadrado como um "sintoma" desse processo. O ponto de partida da trama é, até certo ponto, alinhado à subvertente dos rape \& revenge movies, tendência então em voga no âmbito do horror de exploração internacional após a repercussão e controvérsia despertada por títulos como The last house on the left (Wes Craven, 1972) e I spit on your grave (Meir Zarchi, 1978). A estrutura básica destes filmes é dividida em três momentos: um primeiro, no qual a protagonista feminina sofre abusos físicos e sexuais por parte de um ou mais homens; um eventual "ato intermediário", caracterizado por uma mudança de perspectiva vivenciada pela personagem principal, de feminina para feminista; e um terceiro, em que a vítima (ou personagens próximos a ela) busca algum tipo de reparação ou vingança contra seus estupradores (HELLER-NICHOLAS, 2012; MARINHO; MONTEIRO, 2018) - muito embora, no filme de Garrett, o estupro sirva de catalisador para uma vingança direcionada não exatamente contra o perpetrador de tal ato, mas para todos os homens que atravessam seu caminho.

A profusão de títulos lançados durante a segunda metade dos anos $1970 \mathrm{e}$ estruturados em torno deste leitmotif pôs em evidência as múltiplas ambiguidades que atravessam o discurso de tais filmes, sobretudo pelo fato de condicionarem a agência e o empoderamento das personagens femininas à ocorrência de episódios traumáticos, no mais das vezes filmados de modo a satisfazer o olhar e o desejo do espectador masculino, e nos quais mesmo as "vinganças" são quase sempre encenadas a partir de uma exploração do corpo da mulher em sua condição de arma de sedução.

\section{Gêneros narrativos e marcas estilísticas no cinema de Jean Garrett}

A compreensão destas dinâmicas é fundamental no sentido de situarmos a filmografia de Jean Garrett neste contexto e, particularmente, A mulher que inventou o amor em relação aos demais títulos que compõem a trajetória do diretor. Nascido José Antônio Gomes Nunes da Silva no ano de 1946, em uma ilha do Arquipélago dos Açores, em Portugal, Garrett veio para o Brasil na condição de turista e nunca mais regressou ao país de origem. A criatividade sempre apontada pelos críticos na elaboração dos enquadramentos e a mise-en-scène cuidadosa costumam ser atribuídas à sua experiência pregressa como fotógrafo de moda e autor de fotonovelas, emprego que exerceu em revistas como a Melodias - ainda sob o pseudônimo de Jean Silva - antes de adentrar o mundo do cinema, primeiro como ator e depois como assistente de direção, trabalhando com cineastas como José Mojica Marins e Fauzi Mansur.

Ao longo de 20 anos de carreira na área cinematográfica e tendo dirigido cerca de 18 títulos (numa admirável média de quase dois filmes por ano), Jean Garrett experimentou diferentes gêneros: foi do policial (A ilha do desejo, Amadas e violentadas, 1975) ao horror (Excitação, 1976), da sátira social (Possuídas pelo 
pecado, 1976) ao filme-catástrofe (Noite em chamas, 1977), passando pelo drama psicológico de tons surrealistas (A mulher que inventou o amor, 1979) e pelo thriller sobrenatural (A força dos sentidos, 1979). Seu filme de maior repercussão junto ao público, e possivelmente o mais controverso em função de problemas com a censura, foi o drama vagamente inspirado pelo Relatório Hite e a psicanálise "Mulher, mulher" (1979). Após um ensaio intimista e de viés autobiográfico ( $O$ fotógrafo, 1980) e de dois romances trágicos protagonizados por Angelina Muniz (Karina, objeto de prazer, de 1981, e Tchau, amor, de 1982), Garrett realizou três longas de baixo impacto (A noite do amor eterno, Estranho desejo e Meu homem, meu amante), já sob a sombra do filme de sexo explícito, que começava a se insinuar em simultâneo ao processo de abertura política e de relaxamento da Censura Federal.

A adesão de Jean Garrett à vaga $x$-rated se deu em 1985, com o singular Gozo alucinante, último longa que assina sob o pseudônimo que o consagrou. Curiosamente, e neste aspecto diferindo dos colegas de Boca que também realizaram filmes pornográficos a partir de 1983 adotando "nomes de guerra" algumas vezes cifrados e irreconhecíveis, outras tantas bastante óbvios naquilo que desejavam ocultar (Victor Triunfo/Fauzi Mansur, Geraldo Dominó/Álvaro de Moya, Tony Mel/Antônio Meliande), Garrett assina a direção dos três longas explícitos (Fuk Fuk à brasileira, Entra e sai e O beijo da mulher piranha) que realiza em 1986, antes de se "aposentar" da direção de cinema, como J. A. Nunes, seu nome de batismo. Atuando como administrador do teatro Bibi Ferreira em São Paulo após o declínio da Boca, onde se dedicou a alguns espetáculos infantis, Garrett se tornou vítima da mesma depressão que acometeu diversos realizadores que se viam sem perspectivas de retomarem suas carreiras, tendo falecido por ocasião de um ataque cardíaco em 1996, antes de completar 50 anos de idade.

De todas as alcunhas atribuídas a Jean Garrett, talvez a mais recorrente seja a de artesão: a de alguém inserido em uma lógica que valorizava a produção em série e o manejo consciente dos códigos narrativos de determinados gêneros cinematográficos, mas, ao mesmo tempo, reconhecido como dono de traços estilísticos e/ou estéticos constantes e identificáveis de um filme para outro - o que por sua vez não deixa de revelar algumas das muitas ambivalências que cercam a produção da Boca do Lixo, já que a quase totalidade da obra de Garrett é composta por "filmes de produtor", como Antônio Pólo Galante, David Cardoso, Claudio Cunha e Miguel Augusto de Cervantes (codinome de Manuel Augusto Sobrado Pereira, da MASP Filmes). Tais características, somadas à reconhecida expertise técnica e ao domínio da linguagem audiovisual, em certa medida favoreceriam a recuperação de Jean Garrett como um ponto fora da curva da média de realizadores egressos da região - nem tanto ao mar das elocubrações filosóficas e existenciais de Walter Hugo Khoury ou Carlos Reichenbach, e nem tanto à terra do exploitation instintivo, autodidata e assumidamente popular-massivo de Tony Vieira ou Francisco Cavalcanti (CÁNEPA \& MONTEIRO, 2018).

No contexto destes trânsitos, e mesmo ante a onipresença do apelo erótico demandado pelo circuito exibidor, alguns títulos dirigidos por Jean Garrett conse- 
guiram lograr apropriações muito particulares de elementos horríficos, terríficos e/ou fantásticos - seguindo, aliás, uma tendência bastante comum na história do cinema brasileiro, e que consiste no "mascaramento" de marcas de gênero específicas, pela via da hibridação ou superposição com códigos narrativos de outros gêneros (CÁNEPA, 2006). O longa Excitação, de 1976, é um bom exemplo dessa prática: embora o título sugira uma ênfase nos aspectos sexuais e eróticos da trama (que, decerto, também se fazem presentes), no cerne do roteiro escrito por Garrett e Ody Fraga habita uma história de contornos góticos sobre um suposto fantasma que interfere nos equipamentos eletrodomésticos de uma mansão isolada à beira-mar, levando sua moradora à (quase) loucura (MONTEIRO, 2018b).

\section{Sangue, suor e performatividade de gênero}

Embora estabelecendo conexões mais sutis com este imaginário, $A$ mulher que inventou o amor não deixa de fomentar, à sua maneira, possibilidades de leitura e análise a partir de uma perspectiva horrífica. Sequências como a do estupro no açougue (FIG. 1) e o sacrifício ritual do astro de telenovelas na cena final do filme (FIG. 2 e FIG. 3) denotam o conhecimento de um repertório estilístico que vai do giallo italiano de Mario Bava e Dario Argento, ao terror erótico e sobrenatural franco-espanhol de Jean Rollin, Jesús Franco e José Larraz (passível de ser atribuído à contribuição criativa de Carlos Reichenbach, reconhecido entusiasta destes estilos e outras manifestações paracinemáticas afins, na direção de fotografia).

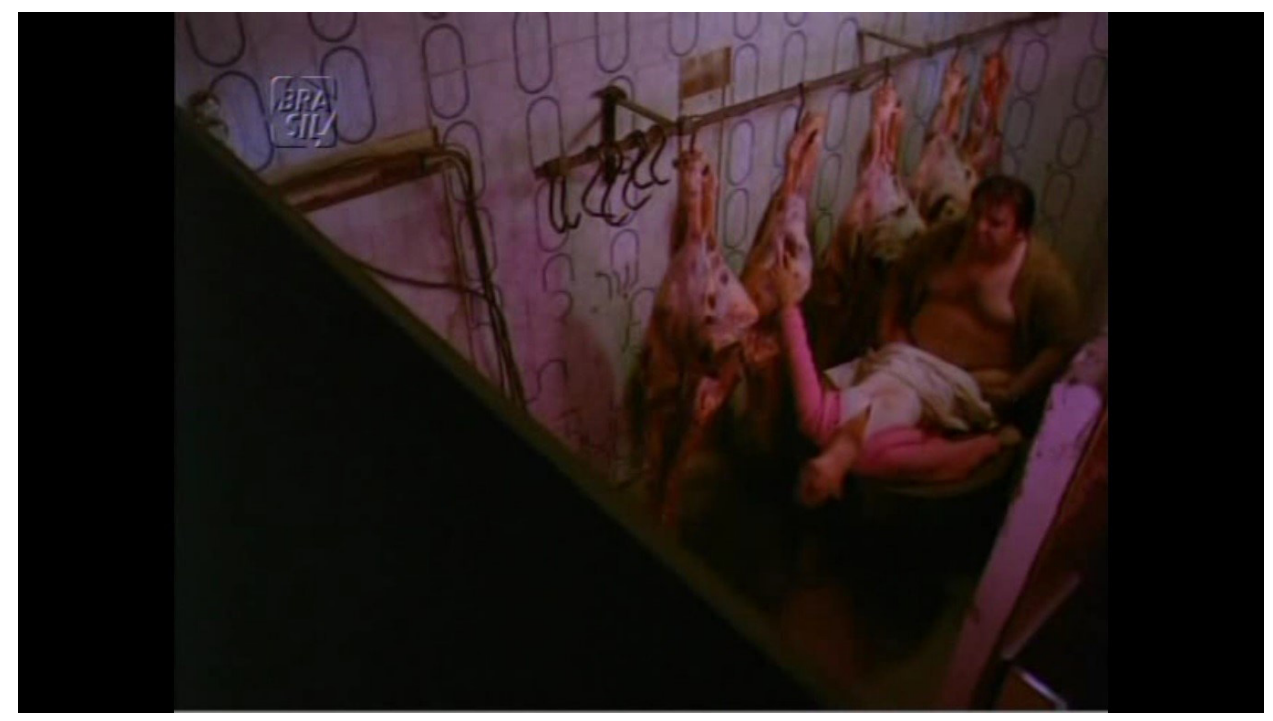

Figura 1: $\mathrm{O}$ estupro no açougue

Fonte: screen capture de versão digital do filme 
Na primeira, a onipresença de uma luz neon piscante e o fato de os personagens estarem rodeados por carcaças de animais mortos reforça o aspecto, ao mesmo tempo, estilizado e abjeto da cena; na segunda, a dupla Garrett/Reichenbach consegue equalizar a simetria nos enquadramentos expressionistas e o recurso ao gore explícito, no qual o sangue de Cesar Augusto, vertendo em profusão após sucessivos golpes de punhal, tinge de um vermelho (propositadamente?) artificial o vestido branco de Doralice/Tallullah - pulsões de Vida e de Morte ensejando uma dança estranha e macabra.
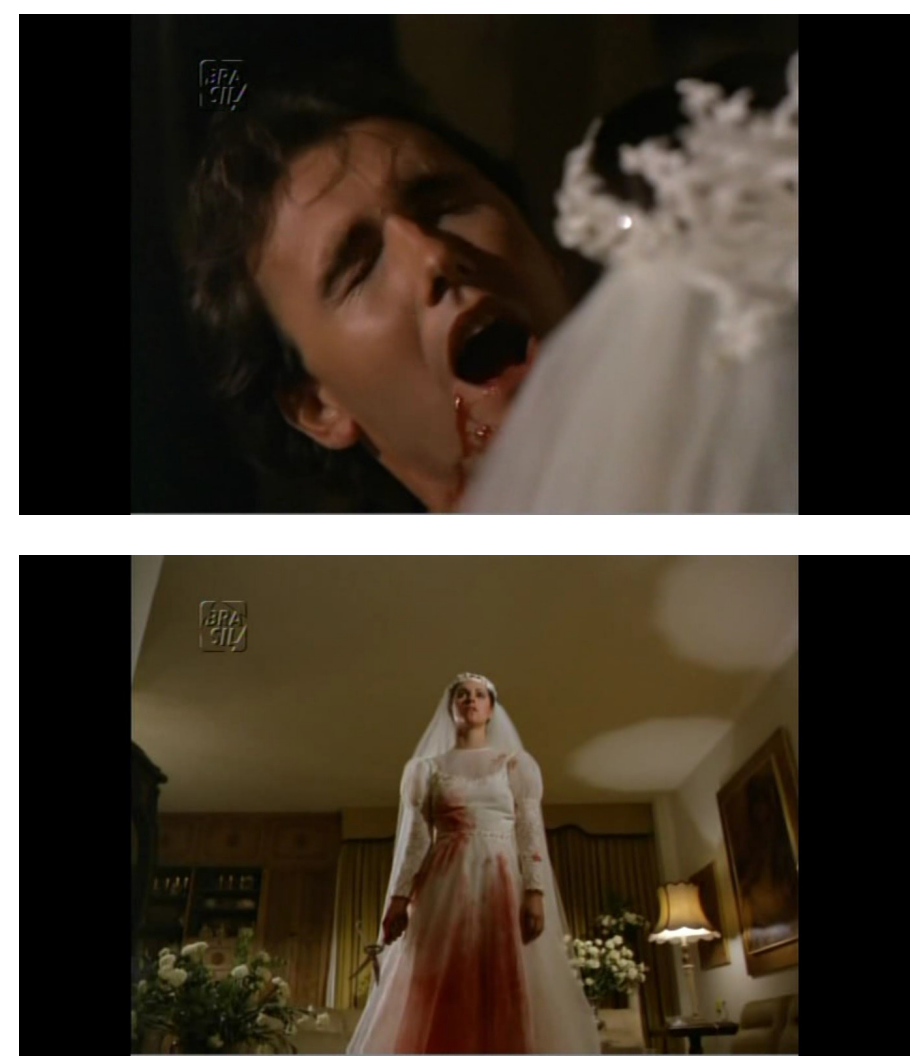

Figuras 2 e 3: O sacrifício de Cesar Augusto e o vestido tingido de sangue

Fonte: Screen captures de versão digital do filme

Também no que concerne às representações de gênero, o filme de Garrett articula propostas, no mínimo, incomuns, sobretudo se comparado ao output padrão da Boca em finais dos anos 1970, quando o processo de abertura política então em curso flexibiliza o aparato censor federal e, gradativamente, tensiona os limites do que pode ser mostrado em termos de nudez e sexo. Se, por um lado, 
esta liberalização favoreceu o reforço de perspectivas objetificadoras sobre o corpo feminino, em obras que tangenciavam a fronteira do pornográfico, por outro lado "A mulher que inventou o amor" parece se aproveitar desta atmosfera para subverter dicotomias e expectativas. Aqui, o crédito deve ser atribuído ao roteiro de João Silvério Trevisan, escritor e jornalista cuja trajetória profissional e artística é caracterizada por um forte ativismo junto aos movimentos LGBT+ brasileiros dos anos 1970, além de algumas contribuições ao cânone do Cinema Marginal do mesmo período, mormente com a realização de "Orgia, ou o homem que deu cria", de 1971 (também fotografado por Carlos Reichenbach).

A sequência da visita ao night club (FIG. 4) é representativa dessa perspectiva não-normativa sobre as questões de gênero e sexualidade, quando assistimos à performance de um artista que se apresenta vestido de noiva e ostetando uma volumosa barba. Após a metamorfose de Doralice em Tallullah, tornam-se frequentes os episódios nos quais a protagonista ora recorre a trajes masculinos como estratégia de sedução (FIG. 5), ora propõe ao(s) parceiro(s) que vista(m) roupas ou execute $(\mathrm{m})$ trejeitos associados a uma ideia de feminino (FIG. 6). A postura da personagem em relação às figuras com as quais se relaciona sexualmente também muda, adquirindo ares de dominância e subjugação durante o ato. Por fim, a revelação da bissexualidade do ídolo Cesar Augusto parece autorizar sua imolação por meio das sucessivas perfurações/penetrações que a lâmina do punhal de Tallulah lhe desfere.

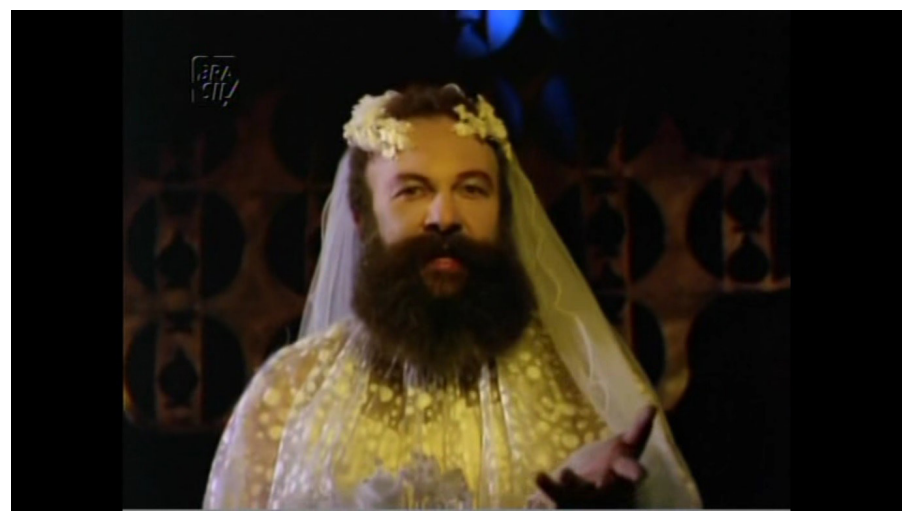

Figura 4 : Sequência do night club Fonte: screen capture de versão digital do filme

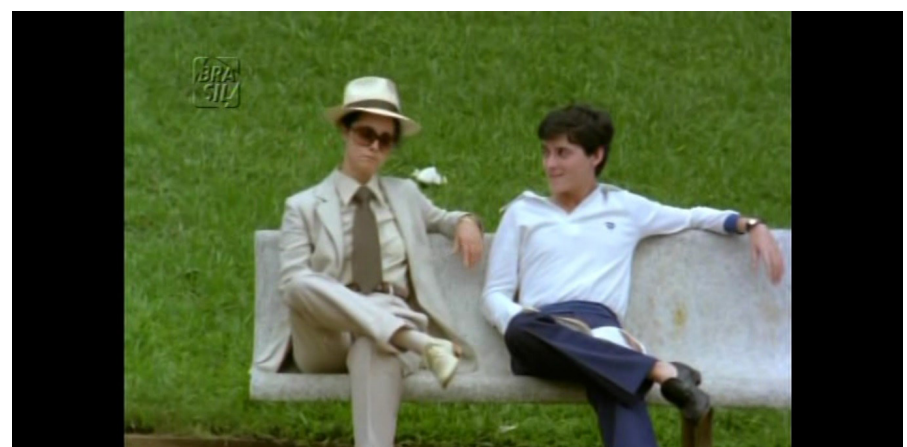


Figura 5: Doralice/Tallulah encenando uma identidade masculina Fonte: screen capture de versão digital do filme

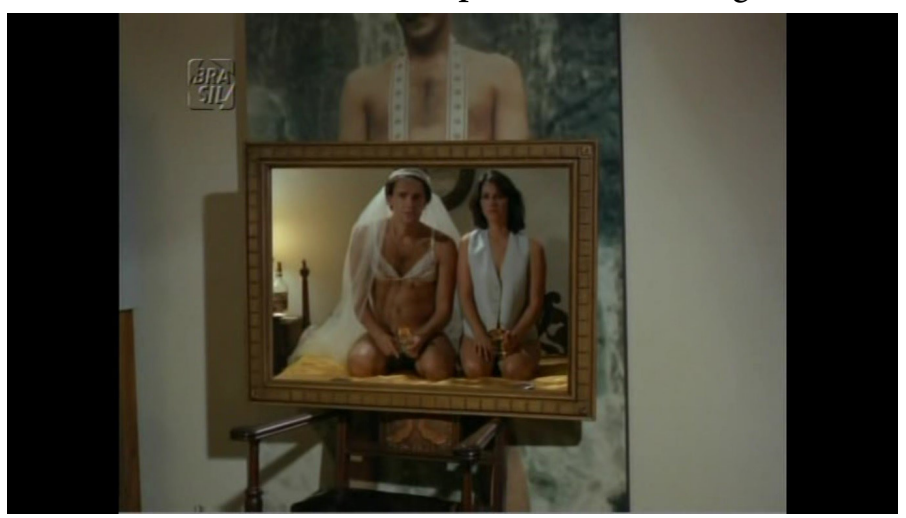

Figura 6: Cesar Augusto se veste de noiva Fonte: screen capture de versão digital do filme

Tantas ambivalências podem estar na origem da recepção nada consensual que o longa-metragem obteve por ocasião de seu lançamento comercial. A tendência da crítica, sobretudo a paulistana, era a de enfatizar as dissonâncias entre $o$ longa de Garrett e aquilo que se esperava de uma produção com o "selo" da Boca do Lixo, como afirmava o crítico Edmar Pereira:

Este é um filme diferente e, em relação aos seus presumíveis semelhantes e concorrentes, absolutamente inesperado. Há citações em profusão, toques feministas, (...) anti-machistas, (...) contra a sexualidade manipulada. (...) Uma lição de 'deserotismo', "irritante, chocante, bonito, desagradável (...), mas nunca menos do que inusitado (PEREIRA, 1980, p. 23).

Já a imprensa mainstream carioca, por sua vez, tendia a ser menos condescendente, enxergando no filme nada mais do que o tradicional repertório da pornochanchada, aqui camuflado sob um verniz pretensamente intelectualizado, como se pode observar nas palavras de Rogéro Biatrelli e de Salviano Cavalcanti 
de Paiva:

Em linhas gerais, os elementos codificados pela pornochanchada estão presentes, mas aqui com a pretensão de uma denúncia à "vilania sexual" (...) onde o kitsch se cruza com uma simplória narrativa sobre o ambiente da prostituição. (...) Carregado nas tintas, (...) o filme não chega a ser uma pornochanchada feminista, apenas outro apelo a signos conhecidos e de fácil identificação por parte do espectador (BIATRELLI, 1980, p. 5).

O diretor Jean Garrett menospreza o espectador menos alvar impingindo-lhe tremenda chacota a título de puxar pelo intelecto: puxa, na verdade, pelos bastiões da escatologia. (...) Este filme é um legítimo exercício de acrobacia. (...) Eros e Thanatos se complementam num mar de sangue visual [que] usa - e abusa (...) - da nossa paciência (PAIVA, 1980, p. 33).

Não por acaso, a leitura mais sensível aos inúmeros subtextos queer do roteiro de João Silvério Trevisan para $A$ mulher que inventou o amor veio justamente da publicação alternativa carioca Lampião da Esquina, que circulou entre finais dos anos 1970 e o princípio da década seguinte, e era tradicionalmente endereçada ao público gay, como se observa na análise feita por Leila Míccolis.

A mulher que inventou o amor é uma crítica muitíssimo bem construída aos usos e costumes eróticos desta e de muitas outras Pátrias amadas. No fundo questiona qual seria a real identidade sexual da mulher sem os manuais dos homens e seus ensinamentos preconceituosos. [O filme] é um enorme diamante bruto, a ser lapidado pela nossa sensibilidade pessoal (MÍCCOLIS, 1980, p. 16).

Poderíamos, assim, apreender $A$ mulher que inventou o amor como o resultado de uma articulação complexa entre a sensibilidade queer do roteiro de João Silvério Trevisan; o tom grotesco, absurdo e excessivo característico das rupturas de linguagem valorizadas pelo udigrudi dos anos 1960 e 1970, de onde provinha Carlos Reichenbach (e o próprio Trevisan); e, por fim, o desejo de comunicação com o grande público pela via do entretenimento e do imaginário de gênero, presente em parte substancial da filmografia de Jean Garrett.

\section{Considerações finais}

Abordar o universo da Boca do Lixo é uma tarefa cercada de armadilhas por 
algumas razões. Primeiro, pelo fato de seu já mencionado silenciamento histórico ser hoje acompanhado por um desejo de legitimação a todo custo que, não raro, produz discursos acríticos acerca das suas dinâmicas de produção. Segundo, porque a negligência com que são tratados os acervos de cinema no Brasil dificulta o acesso a filmes e materiais de arquivo da época. Terceiro, pois em função do estigma atribuído ao cinema erótico popular massivo dos anos 1970 (e sobretudo à guinada hardcore do decênio posterior), muitos dos atores e técnicos atuantes na Boca preferem se distanciar daquele período, abandonando seus acervos e, por vezes, resistindo mesmo a dar entrevistas.

A dificuldade de acesso a informações em primeira mão, somada à falta de referencial bibliográfico sobre esse importante ciclo da história do cinema brasileiro, nos obriga a buscar respostas na prospecção de outros contextos audiovisuais nos quais é possível identificar convergências e aproximações em relação ao que a Boca representava e aos processos que lá se articulavam. Um olhar sobre $A \mathrm{mu}$ lher que inventou o amor nos forneceria, assim, subsídios para uma reflexão crítica acerca das eventuais heranças que a obra teria legado ao cinema de gênero feito no Brasil hoje, bem como sobre a questão do feminino no âmbito da nossa produção audiovisual popular-massiva.

\section{Referências}

ABREU, Nuno César Pereira. Boca do Lixo: cinema e classes populares. Tese (Doutorado em Multimeios) - Universidade Estadual de Campinas, Campinas, 2002.

A MULHER que inventou o amor. Direção: Jean Garrett. Produção: Cassiano Esteves. Intérpretes: Aldine Müller; Zecarlos de Andrade; Rodolfo Arena; Lola Brah; Roberto Miranda; Oslei Delano e outros. Música: Aluísio Pontes. São Paulo: E.C. Distribuição e Importação Cinematográfica; Marte Filmes, 1980. Arquivo digital

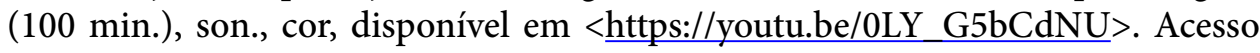
em 26 maio. 2019.

BERNARDET, Jean Claude. A pornochanchada contra a cultura "culta”. In:

Cinema brasileiro: propostas para uma história. São Paulo: Companhia das Letras, 2009. pp. 210-215.

BIATRELLI, Rogério. Carregando nas tintas. Jornal do Brasil. Caderno B, 21 out. 1980, p. 5.

CÁNEPA, Laura Loguércio. Medo de quê? - uma história do horror nos filmes brasileiros. Tese (Doutorado em Multimeios) - Instituto de Artes, UNICAMP. Campinas, 2008.

CÁNEPA, Laura Loguércio; MONTEIRO, Tiago José Lemos. “Você jamais esquecerá esse filme porque você é um dos personagens": Noite em Chamas, os anos 1970 sob as lentes de Jean Garrett. Trabalho apresentado ao GT de Cultura das Mídias no 
XXVII Encontro da Associação Nacional dos Programas de Pós-Graduação em Comunicação, Belo Horizonte, PUC Minas, junho de 2018.

DENNISON, Stephanie. Sex and the Generals: reading Brazilian Pornochanchada as sexploitation. In: RUÉTALO, V.; TIERNEY, D. (org.). Latsploitation, Exploitation Cinemas, and Latin America. New York, London: Routledge, 2009. p. 230-244.

GODINHO, Denise; MOURA, Hugo. Coisas eróticas - a história jamais contada da primeira vez do cinema nacional. São Paulo: Panda Books, 2012.

HELLER-NICHOLAS, Alexandra. Rape-revenge films: a critical study. Jefferson, North Carolina: McFarland \& Company, 2011.

LYRA, Bernardette; SANTANA, Gelson (orgs.). Cinema de bordas. São Paulo: Editora A lápis, 2006.

MARINHO, Larissa de Souza; MONTEIRO, Tiago José Lemos. Percalços de Jennifer(s): uma análise comparativa entre I spit on your grave $e$ Revenge. Trabalho apresentado no IJ04 - Cinema, da Intercom Júnior - XIV Jornada de Iniciação Científica em Comunicação, no $41^{\circ}$ Congresso Brasileiro de Ciências da Comunicação, Joinville, UNIVILLE, 2018.

MÍCCOLIS, Leila. Lampião da esquina, n.31, dez.1980, p.16

MONTEIRO, Tiago José Lemos. Snuff à brasileira: marketing de exploração no cinema da Boca. In: MIGLIORIN, C. et al (org.). Anais de textos completos do XXI Encontro da SOCINE. São Paulo: SOCINE, 2018. p. 680-686.

MONTEIRO, Tiago José Lemos. Ghosts in the machine: supernatural dread vs. technology in the Brazilian erotic horror thriller Excitação (1976). In: GADOMSKA, K.; LOSKA, A.; SWOBODA, A (org.). The supernatural in literature and cinema. Katowice: Wydawnictwo Uniwersytetu Slaskiego, 2018. p. 225-237.

MONTEIRO, Tiago José Lemos. Horror e questões de gênero em A Mulher que Inventou o Amor (1980). In: PRYSTHON, Angela Freire et al (org). Anais de textos completos do XXII Encontro da SOCINE. São Paulo:SOCINE, 2019, p.1029-1034.

ORMOND, Andrea. A mulher que inventou o amor (1979). In: . Ensaios de cinema brasileiro: dos filmes mudos à pornochanchada. São José dos Pinhais, PR: Editora Estronho, 2016. p. 253-254.

PAIVA, Salviano Cavalcanti de. "A mulher que inventou o amor". O Globo. Segundo Caderno, 21 out. 1980, p.33.

PEREIRA, Edmar. Surpresa. Jornal da Tarde, 17 nov. 1980, p.23

PIEDADE, Lúcio de Franciscis dos Reis. A cultura do lixo: horror, sexo e exploração no cinema. 2002. Dissertação (Mestrado em Multimeios) - Instituto de Artes, Universidade Estadual de Campinas, Campinas 2002. 
RAMOS, José Mario Ortiz. Sexo, sangue e emoções masculinas. In:

Cinema, televisão e publicidade: cultura de massa e popular no Brasil nos anos 19701980. São Paulo: Annablume, 2004. p. 178-195.

SCHAEFER, Eric. Bold! Daring! Shocking! True! A History of Exploitation Films, 1919-1959. Durhan \& London: Duke University Press, 1999.

SCONCE, Jeffrey (ed.). Sleaze artists: cinema at the margins of taste, style, and politics. Durham and London: Duke University Press, 2007.

TOHILL, Cathal; TOMBS, Pete. Immoral tales: European sex and horror movies 1956-1984. New York: St. Martin’s Griffin, 1995.

\section{The bride wore red: horror and sexuality in A mulher que inventou o amor}

\section{Abstract}

A mulher que inventou o amor is a Brazilian feature film produced in the area also known as Boca do Lixo (SP), directed by Jean Garrett, written by João Silvério Trevisan and with Carlos Reichenbach as cinematographer. It is a movie which rewrites some stylistics and narrative codes related to genres such as melodrama and horror and, at the same time, discusses gender issues from a singular and transgressive point of view. The main plot deals with the consequences of a rape suffered by Doralice (Aldine Müller), then a young and naive girl, in the opening sequence of the film. The incident starts a revenge against the weak, pathetic and selfish men that cross her path and intefere in her process of inner transformation into Tallulah, a femme fatale which performs gender roles in a disruptive way.

\section{Keywords}

Boca do Lixo; Jean Garrett; "A mulher que inventou o amor"; horror; exploitation. 